\title{
Preferential Solvation of Drugs in Binary Solvent Mixtures
}

\section{Marcus $Y^{*}$}

Institute of Chemistry, Hebrew University of Jerusalem, Jerusalem 91904, Israel

*Corresponding author: Marcus Y, Institute of Chemistry, Hebrew University of Jerusalem, Jerusalem 91904, Israel, Tel: 02-658-5341; Fax: 02-658-5341; E-mail: ymarcus@vms.huji.ac.il

Received date: January 04, 2017; Accepted date: January 20, 2017; Published date: January 23, 2017

Copyright: (c) 2017 Marcus Y. This is an open-access article distributed under the terms of the Creative Commons Attribution License, which permits unrestricted use, distribution, and reproduction in any medium, provided the original author and source are credited.

\begin{abstract}
The preferential solvation of many drugs in binary solvent mixtures, as derived by means of the quasi-lattice quasi-chemical and the inverse Kirkwood-Buff integrals methods from solubility and other thermodynamic data, is reviewed. The preferences were described in terms of the local mole fractions of the solvent components in the solvation sphere of the drug molecule and their differences with respect to these mole fractions in the bulk: the preferential solvation parameters. When data were available at several temperatures these preferences were described in terms of the enthalpic and entropic contributions.
\end{abstract}

Keywords: Drugs; Binary solvent mixtures; Preferential solvation; Quasi-lattice quasi-chemical method; Inverse Kirkwood-Buff integrals method

\section{Introduction}

Most drugs are only poorly soluble in water, and therefore cosolvents have been used in order to enhance their solubility in their production processes. The solubilities of drugs in binary solvent mixtures have been studied extensively by many authors. Many of the studies have been directed towards modeling the solubilities and possibly predicting them from the solubilities in the neat solvents.

The 'nearly ideal binary solvent' (NIBS) approach of Acree et al. has been successful in modeling drug solubilities in some kinds of solvent mixtures [1,2]. However, in mixtures involving polar and non-polar solvents, such as water with co-solvents, the modified model of Jouyban et al. [3] has been more appropriate. Other models, such as those based on surface areas [4], UNIFAC group contributions $[5,6]$, and Hildebrand solubility parameters [7-11], have also been employed. The requirements of the pharmaceutical industry were satisfied by such studies. On the other hand, little insight regarding the actual molecular environment of the drug molecules in the solvent mixture was obtained. The preferential solvation of drug solutes by the components of the solvent mixtures should provide such insight.

This paper reviews the application of two methods, the inverse Kirkwood-Buff integrals (IKBI) method [12,13] and the quasi-lattice quasi-chemical (QLQC) one [14] to solutions of drugs in binary solvent mixtures. These methods present the preferential solvation of the drug molecules by the solvent components. It is stressed that the exact modeling of the solubility curve is not a purpose of such studies, the available methods $[7,10,11]$ being adequate. The purpose is to learn something about the interactions of the solute with the solvent components surrounding its molecules from the preferential solvation.

The preferential solvation parameter for the solute $S$ by the component solvents A and B expresses the results of the preferential solvation (Equation 1):

$\delta \mathrm{xA}, \mathrm{S}=\mathrm{xA}, \mathrm{SL}-\mathrm{xA}=-\delta \mathrm{xB}, \mathrm{S}$ where $\mathrm{xA}$ is the mole fraction of $\mathrm{A}$ in the bulk solvent mixture and $\mathrm{xA}, \mathrm{SL}$ is its local mole fraction in the vicinity of the solute $\mathrm{S}$. If $\delta \mathrm{xA}, \mathrm{S}>0$ then $S$ is preferentially solvated by A, else it is by $\mathrm{B}$. When $|\delta \mathrm{xA}, \mathrm{S}| \leq$ 0.01 the values are within the error of the determination, signifying negligible preferential solvation. Complete selective solvation of S by A takes place when $\delta \mathrm{xA}, \mathrm{S} \approx \mathrm{xB}$, implying that $\delta \mathrm{xA}, \mathrm{S}$ cannot be larger than $\mathrm{xB}$.

Another way to express the preferential solvation is by means of the equilibrium quotient $\mathrm{KAB}$ for the replacement of $\mathrm{A}$ molecules around the solute molecule by B ones. According to the QLQC approach a coordination number $\mathrm{Z}$ (possibly composition dependent, i.e., $\mathrm{Z}(\mathrm{xA})$ ) is assigned to the solute. The solvation numbers by the components are given by $\mathrm{ZxA}, \mathrm{SL}$ for component $\mathrm{A}$ and $\mathrm{Z}(1-\mathrm{xA}, \mathrm{SL})$ for $\mathrm{B}$. The equilibrium quotient is Equation 2:

$$
\mathrm{KAB}=(\mathrm{xA}, \mathrm{SL} / \mathrm{xA}) /[(1-\mathrm{xA}, \mathrm{SL}) /(1-\mathrm{xA})]
$$

However, summarization of the preferential solvation by a single parameter is generally inexpedient.

\section{Details of the Methods}

The preferential solvation of the solute $\mathrm{S}$ in the solvent mixture $\mathrm{A}+\mathrm{B}$ depends not only on the interactions of $\mathrm{S}$ with $\mathrm{A}$ and with $\mathrm{B}$ but also on the mutual interactions of the two solvents as described by GEAB, the molar excess Gibbs energy of their mixing in the absence of S. This aspect has been stressed, e.g., in the preferential solvation of polystyrene in mixed solvent systems [15]. Competitive interactions of all three components take place in the solutions.

Provided the solute $\mathrm{S}$ is only sparingly soluble at all solvent compositions, the molar solubility data of the solute in the neat solvents and their mixture, $\mathrm{s}(\mathrm{S})$, are transformed to the standard molar Gibbs energy of transfer of $\mathrm{S}$ from $\mathrm{A}$ to $\mathrm{A}+\mathrm{B}$ (Equation 3):

$$
\Delta \mathrm{tG} \infty(\mathrm{S}, \mathrm{A} \rightarrow \mathrm{A}+\mathrm{B})=-\mathrm{RT} \ln [\mathrm{s}(\mathrm{S} \text { in } \mathrm{A}+\mathrm{B}) / \mathrm{s}(\mathrm{S} \text { in } \mathrm{A})]
$$

Solute-solute interactions may then be disregarded and the solute molecules are surrounded by solvent molecules only. Otherwise, activity coefficients of $S$ at each solvent composition need to be employed. Another provision for the application of Eq. (3) is that no 
Page 2 of 6

crystal solvates are formed by the solute, so that the identity of the solid that is at equilibrium with the saturated solutions is independent of the solvent composition.

The QLQC approach employs the following expressions according to Marcus $[16,17]$ :

$$
\mathrm{xA}, \mathrm{SL}=1 /[1+(\mathrm{NBB} / \mathrm{NAA}) 1 / 2 \exp (\Delta \mathrm{EAB}, \mathrm{S} / 2 \mathrm{RT})]
$$

Equation 4 arises from the quasi-chemical aspect of the QLQC approach. The quasi-lattice aspect yields the lattice parameter $\mathrm{Z}$ in equation 5-8:

\section{$\mathrm{NBB} / \mathrm{NAA}=[\mathrm{xB}-\mathrm{NAB} / \mathrm{Z}(\mathrm{NA}+\mathrm{NB})] /[\mathrm{xA}-\mathrm{NAB} / \mathrm{Z}(\mathrm{NA}+\mathrm{NB})](5)$}

$\mathrm{NAB} / \mathrm{Z}(\mathrm{NA}+\mathrm{NB})=[1-\{1-\mathrm{xAxB}(1-\exp (-\Delta \mathrm{EAB}$
$\exp (-\Delta \mathrm{EAB} / \mathrm{RT})]$
$\Delta \mathrm{EAB}, \mathrm{S} / \mathrm{RT}=\Delta \mathrm{tG} \infty(\mathrm{S}, \mathrm{A} \rightarrow \mathrm{A}+\mathrm{B}) / \mathrm{Z}$
$\exp (-\Delta \mathrm{EAB} / \mathrm{RT})=[\{2 \exp (-\mathrm{GEAB}(\mathrm{x}=0.5) / \mathrm{ZRT})\}-1] 2$

The numbers NA and NB are the number of molecules of the components in the bulk and NAA, NBB, and NAB the numbers of neighboring pairs of these molecules on the quasi lattice. $\triangle \mathrm{EAB}, \mathrm{S} / \mathrm{RT}$ is the difference in the molar neighboring interaction energies of $S$ with $\mathrm{A}$ and $\mathrm{B}$, according to the molar transfer Gibbs energy of $\mathrm{S}$ from neat solvent $\mathrm{A}$ to neat solvent $\mathrm{B}$ divided by $\mathrm{Z}$, i.e., per neighboring lattice points. $\triangle \mathrm{EAB}$ denotes the molar energy of interaction of molecules $\mathrm{A}$ and $\mathrm{B}$ on neighboring quasi-lattice sites, obtained from the excess Gibbs energy of mixing the components at the equimolar composition. The lattice parameter $\mathrm{Z}$ is a fitting parameter obtained from fitting the complete $\Delta \mathrm{tG} \infty=\mathrm{f}(\mathrm{xA})$ and $\mathrm{GEAB}=\mathrm{f}(\mathrm{xA})$ curves, but a reasonable value to use with the large drug molecules would be equations 9 and 10 .

The experimental solubilities and the derived $\Delta \mathrm{tG} \infty(\mathrm{S}, \mathrm{A} \rightarrow \mathrm{A}+\mathrm{B})$ and also the GEAB of the solvents yield with the set of expressions (4) to (8) the local mole fraction of A xA,SL around the solute molecule $\mathrm{S}$ as a function of the solvent mixture composition. These, $x A, S L$ values then yield the preferential solvation parameters $\delta \mathrm{xA}, \mathrm{S}$ from equation 1 and the equilibrium quotient for solvent replacement $\mathrm{KAB}$ from equation 2.

The IKBI approach according to Ben-Naim [equations 12,13] have been re-cast in the following form [Equations 16,17]:

$$
\begin{aligned}
& \delta \mathrm{xA}, \mathrm{S}=\mathrm{xAxB}(\mathrm{GA}, \mathrm{S}-\mathrm{GB}, \mathrm{S}) /[\mathrm{xAGA}, \mathrm{S}+\mathrm{xBGB}, \mathrm{S}+\mathrm{V} \text { cor }] \\
& \mathrm{GA}, \mathrm{S}=\mathrm{RT} \kappa \mathrm{T}-\mathrm{VS}+\mathrm{xBVBD} / \mathrm{Q} \\
& \mathrm{GB}, \mathrm{S}=\mathrm{RT} \kappa \mathrm{T}-\mathrm{VS}+\mathrm{xAVAD} / \mathrm{Q} \\
& \mathrm{D}=\mathrm{d}[\Delta \mathrm{tG} \infty(\mathrm{S}, \mathrm{A} \rightarrow \mathrm{A}+\mathrm{B})] / \mathrm{dxB} \\
& \mathrm{Q}=\mathrm{RT}+\mathrm{xAxB}(\mathrm{d} 2 \mathrm{GEAB} / \mathrm{dxB} 2)
\end{aligned}
$$

Vcor $=2522.5[\mathrm{rS}+0.1363\{\mathrm{xA}, \mathrm{SLVA}+(1-\mathrm{xA}, \mathrm{SL}) \mathrm{VB}\} 1 / 3-0.085] 3$ (14)

The Kirkwood-Buff integrals GA,S and GB,S are obtained from the thermodynamic data in equations 10 and 11 . The isothermal compressibility of the mixtures (in $\mathrm{GPa}-1$ ) is $\kappa \mathrm{T}$, given to sufficient approximation as the linear expression $\mathrm{xA \kappa T} \mathrm{A}+\mathrm{xB \kappa \textrm {T }} \mathrm{B}$. The partial molar volumes are VS of the solute, and VA and VB of the solvents and may be replaced to a good approximation by the molar volumes of the pure substances (in $\mathrm{cm}^{3} \mathrm{~mol}^{-1}$ ). The derivative expressions $\mathrm{D}$ and $\mathrm{Q}$ in equations 12 and 13 are to be obtained in $\mathrm{kJ} \mathrm{mol}^{-1}$, as is RT. The correlation volume around $\mathrm{S}$, within which preferential solvation takes place, is Vcor from eq. (14), in $\mathrm{cm}^{3} \mathrm{~mol}^{-1}$, the same units in which GA,S and GB,S are to be expressed. The calculation of the correlation volume requires iteration, because it depends on the local mole fractions given by equations 1 and 9 . The numerical values in equation 14 are valid for the radius of the solute, $\mathrm{rS}$, in $\mathrm{nm}$ (calculated from VS with a packing factor of 58\%, according to notions in Marcus [17]) and pertain to the solute with one solvation shell.

It should be noted that The QLQC approach is less rigorous than the IKBI one, depending on a lattice model for the solution and assumptions concerning the interactions of neighboring species. On the other hand, for the QLQC method only the standard molar transfer energy between the neat solvents is needed, contrary to the IKBI method that requires the derivative of the full $\Delta \mathrm{tG} \infty=\mathrm{f}(\mathrm{xA})$ curve, and only the excess Gibbs energy of mixing of the equimolar solvent mixture, $\mathrm{GEAB}(\mathrm{x}=0.5)$ is needed, contrary to the IKBI method that requires the second derivative of the full $\mathrm{GEAB}=\mathrm{f}(\mathrm{xA})$ curve. Therefore, the IKBI method requires very precise thermodynamic and solubility data for the calculation of the derivatives for the quantities D and Q.

\section{Applications}

The application of the QLQC and IKBI methods for obtaining the preferential solvation of drug molecules in binary solvent mixtures is reviewed in this section. No attempt to be exhaustive has been made, and the studies are from a single school of investigation, extending over nearly a decade.

Both approaches could be employed with congruous results [18] regarding the solubilities of caffeine and niflumic acid in mixtures of ethyl acetate and ethanol, with data provided by Bustamante et al. [19]. The resulting values of the parameter for the preferential solvation of the drugs by the ethanol component, as a function of the ethanol mole fraction are shown in Figure 1. Both drugs prefer ethanol at lower contents but ethyl acetate at higher ones of the protic component. However, differences in the results from the IKBI and QLQC approaches were obtained [17] when the solubilities of these two drugs in mixtures of water with ethanol [19] were examined. The results are in agreement qualitatively, but the positions of the maxima and the shapes of the curves differ. Both methods show that ethanol is preferred by the niflumic acid over water in its near environment at all solvent compositions, but only at low ethanol contents caffeine prefers it in its environment over water, and at high ones water is somewhat preferred.

The solubilities of diazepam and benzocaine in mixtures of water and ethanol were measured by Rubino and Yalkowsky [20]. Preference of ethanol over water is exhibited by both methods, somewhat larger for diazepam than for benzocaine, but the positions of the maxima in $\delta \mathrm{xS}$,EtOH differ [17]. The solubilities of these two drugs were also measured by Rubino et al. in mixtures of water with 1,4-dioxane (DX) [21]. The QLQC method leads to preference for dioxane over water over the entire composition range [17]. The IKBI method produces an unexplained break in the curve near the solvent equimolar composition for benzocaine, resulting from the shape of the derivative of the Gibbs energy of transfer data obtained from the solubility ratios [21], arising from lack of data in the range $\mathrm{xDX}>0.65$, as explained [17].

The solubilities of paracetamol, phenacetin, and nalidixic acid in mixtures of water with 1,4-dioxane have been studied by Bustamante et al. $[22,23]$. The preference of these drugs for dioxane derived from both approaches increases in the listed order [17]. 
Page 3 of 6

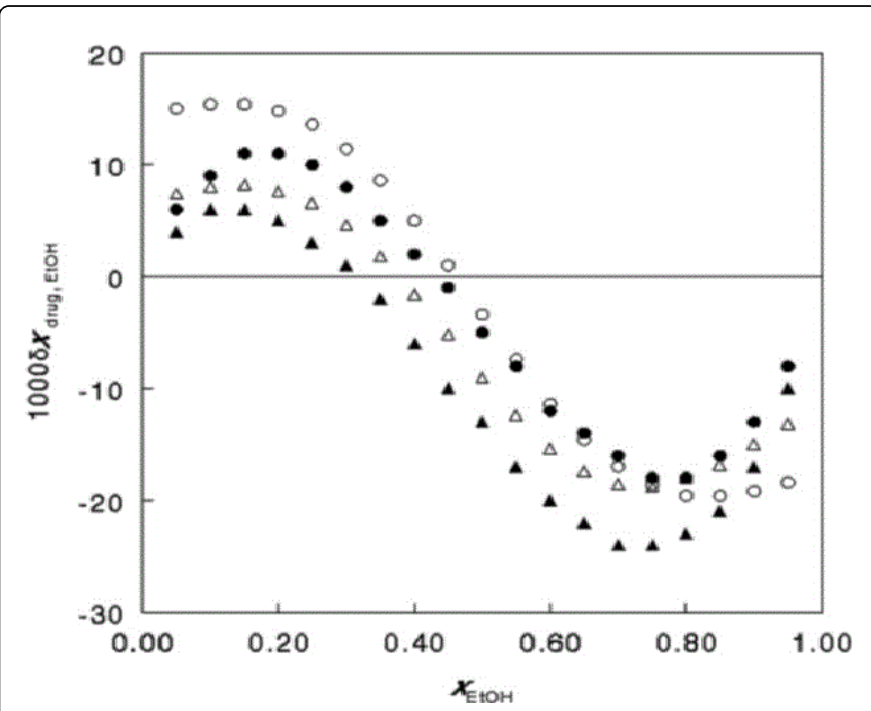

Figure 1: The preferential solvation parameter for the solvation in mixtures of ethyl acetate and ethanol of niflumic acid (circles) and caffeine (triangles) by the ethanol, as obtained by the QLQC (filled symbols) and IKBI (empty symbols) approaches [17].

The solubilities of the ibuprofen and naproxen in the mixtures of water and 1,2-propylene glycol (PG) were provided by Manrique et al. [24] solute-solute interactions, but that of ibuprofen is considerable at the higher temperatures, but no activity coefficient data are available. No excess Gibbs energies of mixing have been reported for the water + PG system, but such values can be derived from published water activities data, as shown by Marcus [25], where also the manners of obtaining the necessary thermodynamic data for the application of the IKBI method are reported. Both the QLQC and IKBI methods indicate that PG is preferred over water in the surroundings of both drug molecules, of ibuprofen more than of naproxen, although the preference is not large. A small increase of the preferences with increasing temperatures was noted. Ibuprofen has a hydrophilic head, the carboxylic group, and a hydrophobic tail. Naproxen has in addition to the hydrophilic carboxylic acid head also a methoxy group in the, albeit more bulky, hydrophobic tail. Neat PG solvated both drugs many times better than water, which has a more pronounced and stiff network of hydrogen bonds than PG. The molecules of the solvent components interact more strongly with each other than with their own kind, as shown by the negative Gwater, PGE values. This interaction loosens the tight hydrogen bond network of the water and facilitates the inclusion of the drug molecules, in addition to the direct solvation of the polar groups. The result is a preferential solvation of both drug molecules by PG at all compositions, but not as much as would have been suggested by the differences in the solvation abilities of the neat solvent components [25].

The school of investigations involving Martinez et al. in Colombia is responsible for a large body of information concerning the preferential solvation of drugs in binary solvent mixtures. The solubility of another drug, meloxicam, in aqueous PG mixtures was studied by Holguin et al. [26] at several temperatures from 20 to $40^{\circ} \mathrm{C}$ and its preferential solvation was derived by the IKBI method. The solubility was maximal in neat propylene glycol and very low in pure water at all temperatures studied. The driving mechanism for meloxicam solubility in the waterrich mixtures was the entropy, due to water-structure loss around nonpolar moieties of the drug, while for the propylene glycol-rich mixtures it was the enthalpy, due to better solvation of the drug. Rather small preferential solvation of meloxicam by propylene glycol was observed at all compositions.

The preferential solvation of meloxicam in four other solvent mixtures was also studied: in mixtures of ethanol and ethyl acetate (EA) [27], of water and methanol [28], of water and ethanol [29], and of water with 1,4-dioxane (DX) [30]. The former of these studies involved the equilibrium solubility of meloxicam at five temperatures from 20 to $40^{\circ} \mathrm{C}$. Preferential solvation parameters of the drug were derived by means of the IKBI method. The preferential solvation parameter by ethyl acetate is $\delta \mathrm{xS}, \mathrm{EA}<0$ in ethanol-rich mixtures but $>0$ at $0.38<\mathrm{xEA}<0.80$. In the former region the interaction by acidic hydrogen-bonding by ethanol on the basic sites of meloxicam plays a relevant role in the drug solvation. The slight preference of this drug for ethanol in ethyl acetate-rich mixtures was explained in terms of the common participation of basic sites in both solvents and/or the acidic site of ethanol with the respective counterparts of meloxicam [27].

Figure 2 shows the preferential solvation parameters $\delta \mathrm{xS}, \mathrm{A}$ values for meloxicam in several binary aqueous/co-solvent mixtures at 298.15 $\mathrm{K}$ obtained by the IKBI method. The diverging values for aqueous dioxane are due to the apparent divergence observed in the GS, water integrals due to the large negative values of $\mathrm{D}$. All the curves show preferential solvation by water (solvent $B$ ) in water-rich mixtures, $\delta \mathrm{xS}, \mathrm{A}<0$, and preferential solvation by the co-solvent (solvent $\mathrm{A}$ ), $\delta \mathrm{xS}, \mathrm{A}>0$, at the intermediate compositions up to the neat co-solvent, but ethanol has $\delta \mathrm{xS}, \mathrm{A}<0$ at the ethanol-rich compositions, which fact is not readily understood.

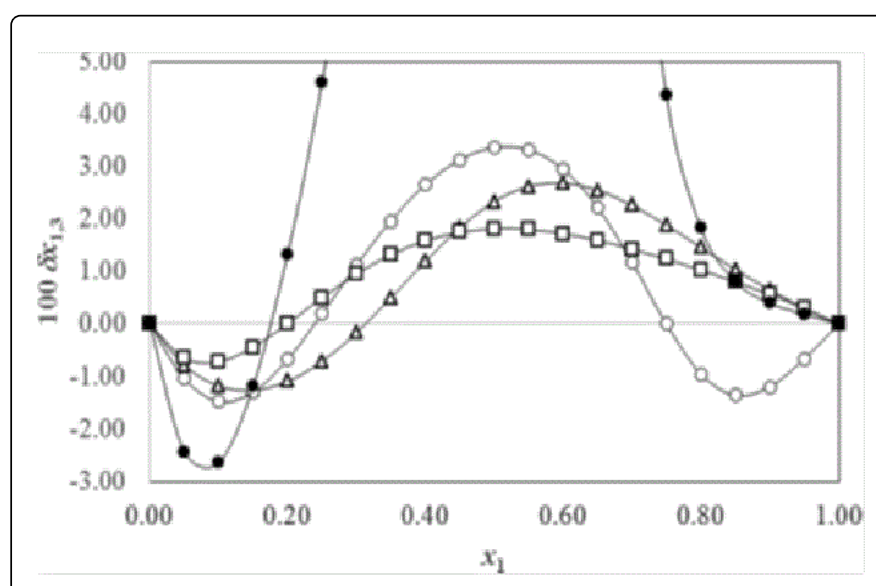

Figure 2: The preferential solvation $\delta \times 1,3$ ( $\delta$ xsolvent 1 ,solute) of meloxicam in aqueous/co-solvent mixtures. Solvent 1 is: 1,4dioxane, methanol, $\circ$ ethanol, and propylene glycol. Reprinted with permission [30]. Copyright 2014 American Chemical Society.

Ruidiaz et al. [31] applied both the QLQC and the IKBI methods to the solubility of indomethacine in mixtures of water with 1,4-dioxane (DX) at several temperatures between $2^{\circ} \mathrm{C}$ and $4^{\circ} \mathrm{C}$. It was concluded that hydrogen bonding of the carboxylate group of indomethacine to the more basic solvent component, 1,4-dioxane, causes the latter to solvate the drug molecules preferentially, but also the strong selfinteraction of the water molecules hinders the introduction of the bulky solute. Entropy-driving takes place for the solution processes up to 0.60 mass fraction of 1,4-dioxane, whereas, beyond this proportion enthalpy-driving occurs. 
Page 4 of 6

The preferential solvation parameter of indomethacin was studied also in ethyl acetate (EA+ethanol mixtures by the inverse KirkwoodBuff integrals method [32]. The preferential solvation parameter, $\delta \mathrm{xS}, \mathrm{EA}$, is negative in ethanol-rich and ethyl acetate-rich mixtures but positive in compositions from $0.36<\mathrm{xEA}<0.71$. In ethanol-rich mixtures, the acidic interaction of ethanol on basic sites of the drug plays a relevant role in the solvation. The better solvation by ethyl acetate in mixtures of comparable compositions of the solvents was attributed to polarity effects. The slight preference of the drug for ethanol in ethyl acetate-rich mixtures was attributed to the participation of basic sites in both solvents and the acidic site of ethanol. Naproxen was found to behave in these solvent mixtures in the same manner as indomethacine [32].

The preferential solvation of methocarbamol in a series of mixtures of co-solvents (A): dioxane, ethanol, methanol, and propylene glycol with water (B) was derived from their thermodynamic properties by using the IKBI method [33]. This drug is sensitive to solvation effects, the preferential solvation parameter $\delta \mathrm{xS}, \mathrm{A}$, is negative in water-rich and co-solvent-rich mixtures, but positive in mixtures with similar proportions of solvents. An exception is methanol+water mixtures, where positive values are found in the methanol-rich mixtures. The hydrophobic hydration around the non-polar groups in water-rich mixtures plays a relevant role. The drug is mainly solvated by the cosolvent in mixtures of similar solvent compositions due to the basic sites of the co-solvents; whereas in co-solvent-rich mixtures the preferential solvation by water is attributed to the acidic nature of water.

The preferential solvation of several sulfa-drugs in solvent mixtures has been studied recently. The solubility of sulfadiazine [34], sulfamerazine [35], and sulfamethazine [36] in methanol+water mixtures was measured at five temperatures from 20 to $40^{\circ} \mathrm{C}$. A nonlinear enthalpy-entropy relationship was observed: the driving mechanism for dissolution of these drugs in water-rich mixtures was the entropy, but from the mass fraction $w \mathrm{MeOH}>0.20$ (from $w \mathrm{MeOH}>0.70$ in the case of sulfamethazine) to neat methanol the process was enthalpy-driven. The preferential solvation of these drugs by the solvents was analyzed by means of the IKBI method: it was preferentially solvated by water in water-rich mixtures but preferentially solvated by methanol in methanol-rich mixtures. A similar study of the solubility of sulfadiazine in 1,4-dioxane +water mixtures [37] showed that the driving mechanism for the dissolution process was the enthalpy in nearly all the compositions. The preferential solvation of this drug was analyzed by means of the IKBI method, showing that it was preferentially solvated by water in waterrich and 1,4-dioxane-rich mixtures but preferentially solvated by 1,4 dioxane in those mixtures with intermediate compositions.

The preferential solvation parameters of several anti-inflamatory drugs: naproxen, ketoprofen, and ibuprofen in methanol+water binary mixtures were derived by means of the IKBI method from their solubilities at $25^{\circ} \mathrm{C}$ [38]. These drugs are very sensitive to specific solvation effects. The preferential solvation parameters by methanol $\delta \mathrm{xS}, \mathrm{MeOH}$ are negative in water-rich mixtures, but positive at compositions from $\mathrm{xMeOH}=0.32$ to pure methanol. In the former region the hydrophobic hydration around aromatic rings and/or methyl groups plays a dominant role in the solvation. The higher solvation by methanol at $\mathrm{xMeOH}>0.32$ was explained in terms of the higher basicity of methanol interacting with the hydroxyl group of the drugs.
Preferential solvation parameters of etoricoxib in several aqueous co-solvent mixtures, involving 1,4-dioxane, N,N-dimethylacetamide, 1,4-butanediol, N,N-dimethylformamide, ethanol and dimethyl sulfoxide (solvent A), were calculated from solubilities and other thermodynamic data by the IKBI method [39]. Etoricoxib was preferentially solvated by water in water-rich and co-solvent-rich mixtures, $\delta \mathrm{xS}, \mathrm{A}<0$, but in mixtures with similar proportions of both solvents $\delta \mathrm{xS}, \mathrm{A}>0$ was found. Hydrophobic hydration in water-rich mixtures plaid a dominant role in the drug solvation. In mixtures of similar solvent proportions the drug acted as a Lewis acid with the more basic co-solvents. In cosolvent-rich mixtures the preferential solvation by water was due to the relatively higher acidity of water. No relation between preferential solvation magnitude and co-solvent polarities was observed.

The preferential solvation of the anti-cancer drug ibrutinib in mixtures of ethanol and water [40] and of 2-(2-ethoxyethoxy) ethanol and water [41] at saturation in the solvent mixtures was studied, based on the inverse IKBI method. Addition of ethanol (A) to water (B) yields negative the $\delta \mathrm{xS}, \mathrm{A}$ values up to the mixture $\mathrm{xEtOH}=0.24$ reaching minimum values at $\mathrm{xEtOH}=0.10$. Hydrophobic hydration around the non-polar groups of ibrutinib contributes to lowering the $\delta \mathrm{xS}, \mathrm{A}$ to negative values in these water-rich mixtures. On the other hand, when $0.24<\mathrm{xEtOH}<1.00$, the $\delta \mathrm{xS}, \mathrm{A}$ values are positive. The action of the co-solvent to increase the solubility of ibrutinib was related to the breaking of the ordered structure of water around the non-polar moieties of the solute and also ibrutinib was acting as a Lewis acid with ethanol that is more basic than water. The magnitudes of preferential solvation by ethanol diminish with increasing temperatures as has been also been reported for some sulfonamides in these solvent mixtures [35]. The behavior of ibrutinib in mixtures of 2(2-ethoxyethoxy) ethanol (A) and water (B) [41] is similar, except that a sharp minimum of $\delta \mathrm{xS}, \mathrm{A}$ at $\mathrm{xA}=0.05$ occurs and it turns positive at $\mathrm{xA}>0.15$.

\section{Discussion}

Few investigations other than those summarized above deal directly with the preferential solvation of drug molecules in binary solvent mixtures, and these employ neither the QLQC nor the IKBI method. One such study was that of Shehatta [42] that related deviations from the linear solvation energy relationships observed with several solvatochromic indicators in aqueous ethanol mixtures to those of the drug Trazodone. A more recent study by Boroujeni and Gharib [43] involved the drug Deferiprone as the solvatochromic probe in several aqueous co-solvent mixtures: with methanol, ethanol, 2-propanol, 1propanol, acetonitrile, and dioxane.

The large body of studies on the preferential solvation of drugs in binary solvent mixtures, however, involves the QLQC and mainly the IKBI methods. These dealt with solutions of a large variety of drugs in (mainly aqueous) mixtures of bio-compatible solvents. Depending on the presence of acidic (hydrogen bond donating) sites and/or basic (hydrogen bond accepting) sites on the drug molecules, the solvation of the drug by basic and respectively acidic solvents contributes to the enthalpic aspect of its solubilization. Another contribution to this aspect is the accommodation of the bulky drug molecules in the hydrogen-bonded network, in particular of the aqueous component of the solvent mixture. On the other hand, the entropic aspect involves the release of solvent molecules from such networks to become freely moving particles. These, sometimes conflicting, modes of interaction 
Page 5 of 6

dictate the final picture of the preferential solvation, as is illustrated in Figures 1 and 2 .

Table 1 summarizes the studies of the preferential solvation of drugs in binary solvent mixtures dealt with in this paper.

\begin{tabular}{|c|c|c|}
\hline Drug & Solvents & Reference \\
\hline Benzocaine & Water+ethanol+1,4-dioxane & 17 \\
\hline Caffeine & Ethanol+ethyl acetate & 17 \\
\hline Diazepam & Water+ethanol+1,4-dioxane & 17 \\
\hline Etoricoxib & $\begin{array}{l}\text { Water+ethanol+1,4-dioxane+1,4- } \\
\text { butanediol+dimethyl-formamide } \\
\text { +dimethylacetamide+dimethyl sulfoxide }\end{array}$ & 39 \\
\hline Ibrutinib & Water+ethanol & 40 \\
\hline Ibrutinib & Water+2-ethoxy-(2-ethoxy)ethanol & 41 \\
\hline Ibuprofen & Water+1,2-propanediol & 25 \\
\hline Ibuprofen & Water+methanol & 38 \\
\hline Indomethacine & Water+1,4-dioxane & 31 \\
\hline Indomethacine & Ethanol+ethyl acetate & 32 \\
\hline Ketoprofen & Water+methanol & 38 \\
\hline Meloxicam & Water+methanol & 28 \\
\hline Meloxicam & Water+ethanol & 29 \\
\hline Meloxicam & Water+1,4-dioxane & 30 \\
\hline Meloxicam & Water+1,2-propanediol & 26 \\
\hline Meloxicam & Ethanol+ethyl acetate & 27 \\
\hline Methocarbamol & $\begin{array}{c}\text { Water+methanol+ethanol+1,4-dioxane } \\
+1,2 \text {-propanediol }\end{array}$ & 33 \\
\hline Naldixic acid & Water+1,4-dioxane & 17 \\
\hline Naproxen & Water+1,2-propanediol & 25 \\
\hline Naproxen & Ethanol+ethyl acetate & 33 \\
\hline Naproxen & Water+methanol & 38 \\
\hline Niflumic acid & Ethanol+ethyl acetate & 17 \\
\hline Paracetamol & Water+1,4-dioxane & 17 \\
\hline Phenacetine & Water+1,4-dioxane & 17 \\
\hline Sulfadiazine & Water+methanol & 34 \\
\hline Sulfadiazine & Water+1,4-dioxane & 37 \\
\hline Sulfamerazine & Water+methanol & 35 \\
\hline Sulfamethazine & Water+methanol & 36 \\
\hline
\end{tabular}

Table 1: Summary of the drugs and binary solvent mixtures dealt with here.

\section{Conclusion}

Many models have been proposed for description and eventual prediction of the solubility of drugs in binary solvent mixtures. Such mixtures are useful for the production, separation, and formulation of drugs, since they are generally only sparingly soluble in the solvent of physiological importance: water. The understanding of the interactions of the drug molecules with the solvent components (and of these among themselves) is essential for a better ability of the selection of suitable co-solvents. The preferential solvation of the drug molecules by the solvent components that is provided by the QLQC and IKBI methods described in this review contributes strongly to this understanding. Both the enthalpic and the entropic aspects of the dissolution of the drugs in the binary solvent mixtures can be derived from these studies, carried out at several temperatures.

\section{References}

1. Acree WE Jr, Rytting JH (1982) Solubility in binary solvent systems. I: Specific versus nonspecific interactions. J Pharm Sci 71: 201-205.

2. Jouyban-Gharasmaleki A, Valace L, Barzegar-Jalali M, Clark BJ, Acree WE (1999) Comparison of various cosolvency models for calculating solute solubility in water-cosolvent mixtures. Int J Pharm 177: 93-101.

3. Jouyban A, Khoubnasabiafari M, Acree WE Jr (2006) Predicting solubility of anthracene in non-aqueous solvent mixtures using a combination of Jouyban-Acree and Abraham models. Chem Pharm Bull 54: 1124-1130.

4. Acree WE Jr, Rytting JH (1983) Solubility in binary solvent systems. III: Predictive expressions based on molecular surface areas. J Pharm Sci 72: 292-296.

5. Acree WE Jr, Rytting JH (1983) Solubility in binary solvent systems. IV, Prediction of naphthalene solubilities using the LJNIFAC group contribution model. Int J Pharm 13: 197-204.

6. Subrahmanyam CVS, Sarasija S (1997) Solubility behavior of carbamazepine in binary solvents. Extended Hildebrand solubility approach to obtain solubility and other parameters. Pharmazie 52: 939-942.

7. Martin A, Newburger J, Adjei AJ (1980) Extended Hildebrand solubility approach: solubility of theophylline in polar binary solvents. J Pharm Sci 69: 487-491.

8. Martin A, Miralles MJ (1982) Extended Hildebrand solubility approach: solubility of tolbutamide, acetohexamide, and sulfisomidine in binary solvent mixtures. J Pharm Sci 71: 439-442.

9. Pena MA, Reillo A, Escalera B, Bustamante P (2006) Pharmaceutical nanotechnology: solubility parameter of drugs for predicting the solubility profile type within a wide polarity range in solvent mixtures. Int J Pharm 321: 155-161.

10. Acree Jr WE, Tucker SA (1994) Thermochemical investigations of hydrogen-bonded solutions Part 6. Comparison of mobile order theory versus Kretschmer-Wiebe association model for describing anthracene solubilities in binary hydrocarbon+alcohol solvent mixtures. Fluid Phase Equilib 102: 17-29.

11. Ruckenstein E, Shulgin IL (2003) Solubility of drugs in aqueous solutions Part 1. Ideal mixed solvent approximation. Int J Pharm 258: 193-201.

12. Ben-Naim A (1988) Theory of preferential solvation of nonelectrolytes. Cell Biophys 12: 255-269.

13. Ben-Naim A (1990) Preferential solvation in two- and in threecomponent systems. Pure Appl 62: 25-34.

14. Marcus Y (1983) A quasi-lattice quasi-chemical theory of preferential solvation of ions. Aust J Chem 36: 1719-1738.

15. Aminabhavi TM, Munk P (1979) Preferential adsorption onto polystyrene in mixed solvent systems. Macromol 12: 607-613.

16. Marcus Y (2002) Solvent Mixtures: Properties and Preferential Solvation, CRC Press, NY, USA, p:258. 
Page 6 of 6

17. Marcus Y (2008) On the preferential solvation of drugs and PAHs in binary solvent mixtures. J Mol Liq 140: 61-67.

18. Marcus Y (2003) The sizes of molecules-revisited. J Phys Org Chem 16: 398-408.

19. Bustamante P, Navarro J, Romero S, Escalera B (2002) Thermodynamic origin of the solubility profile of drugs showing one or two maxima against the polarity of aqueous and nonaqueous mixtures: niflumic acid and caffeine. J Pharm Sci 91: 874-883.

20. Rubino JT, Yalkowsky SH (1985) Solubilization by cosolvents. III: diazepam and benzocaine in binary solvents. J Parenter Sci Technol 39: 106-111.

21. Rubino JT, Blanchard J, Yalkowsky SH (1987) Solubilization by cosolvents IV: benzocaine, diazepam and phenytoin in aprotic cosolvent-water mixtures. J Parenter Sci Technol 41: 172-176.

22. Bustamante C, Bustamante P (1996) Nonlinear enthalpy-entropy compensation for the solubility of phenacetin in dioxane-water solvent mixtures. J Pharm Sci 85: 1109-1111.

23. Bustamante P, Romero S, Pena A, Escalera B, Reillo A (1998) Enthalpyentropy compensation for the solubility of drugs in solvent mixtures: paracetamol, acetanilide, and nalidixic acid in dioxane-water. J Pharm Sci 87: 1590-1596.

24. Manrique YJ, Pacheco DP, Martinez F (2008) Thermodynamics of Mixing and Solvation of Ibuprofen and Naproxen in Propylene Glycol+Water Cosolvent Mixtures. J Solution Chem 37: 165-181.

25. Marcus Y (2009) Preferential solvation of ibuprofen and naproxen in aqueous 1,2-propanediol. Acta Chem Sloven 56: 40-44.

26. Holguín AR, Delgado DR, Martínez F, Marcus Y (2011) Solution thermodynamics and preferential solvation of meloxicam in propylene glycol+water mixtures. J Solution Chem 40: 1987-1999.

27. Cristancho DM, Martínez F (2014) Solubility and preferential solvation of meloxicam in ethyl acetate+ethanol mixtures at several temperatures. J Mol Liq 200: 122-128.

28. Delgado DR, Jouyban A, Martínez F (2014) Solubility and preferential solvation of meloxicam in methanol+water mixtures at $298.15 \mathrm{~K}$. J Mol Liq 197: 368-373.

29. Delgado DR, Holguín AR, Martínez F, Marcus Y (2011) Solubility and preferential solvation of meloxicam in ethanol+water mixtures. Fluid Phase Equil 305: 88-95.

30. Jiménez DM, Cárdenas ZJ, Delgado DR, Jouyban A, Martínez F (2014) Solubility and solution thermodynamics of meloxicam in 1,4-dioxane and water mixtures. Ind Eng Chem Res 53: 16550-16558.

31. Ruidiaz MA, Delgado DR, Martínez F, Marcus Y (2010) Solubility and preferential solvation of indomethacin in 1,4-dioxane+water solvent mixtures. Fluid Phase Equi 299: 259-265.
32. Rodríguez GA, Delgado DR, Martínez F (2014) Preferential solvation of indomethacin and naproxen in ethyl acetate+ethanol mixtures according to the IKBI method. Phys Chem Liq 52: 533-545.

33. Jiménez DM, Cárdenas ZJ, Delgado DR, Martínez F, Jouyban A (2014) Preferential solvation of methocarbamol in aqueous binary co-solvent mixtures at $298.15 \mathrm{~K}$. Phys Chem Liq 52: 726-737.

34. Delgado DR, Martínez F (2014) Solubility and preferential solvation of sulfadiazine inmethanol+water mixtures at several temperatures. Fluid Phase Equil 379: 128-138.

35. Delgado DR, Martınez F (2015) Solution thermodynamics and preferential solvation of sulfamerazine in methanol+water mixtures. J Solution Chem 44: 360-377.

36. Delgado DR, Almanza OA, Martínez F, Pena MA, Jouyban A, et al. (2016) Solution thermodynamics and preferential solvation of sulfamethazine in (methanol+water) mixtures. J Chem Thermodyn 97: 264-276.

37. Jimenez DM, Cardenas ZJ, Delgado DR, Pena MA, Martínez F (2015) Solubility temperature dependence and preferential solvation of sulfadiazine in 1,4-dioxane+water co-solvent mixtures. Fluid Phase Equil 397: 26-36.

38. Jimenez DM, Munoz MM, Rodriguez CJ, Cardenas ZJ, Martínez F (2016) Solubility and preferential solvation of some non-steroidal antiinflammatory drugs in methanol+water mixtures at $298.15 \mathrm{~K}$. Phys Chem Liq 54: 686-702.

39. Martínez F, Jouyban A, Acree WE Jr (2016) Preferential solvation of etoricoxib in some aqueous binary cosolvent mixtures at $298.15 \mathrm{~K}$. Phys Chem Liq.

40. Martinez F, Jouyban A, Acree WE Jr (2016) Further numerical analysis on the solubility of ibrutinib in ethanol+water mixtures at different temperatures. J Mol Liq 218: 35-38.

41. Martinez F, Jouyban A, Acree WE Jr (2016) Comments on "Solubility and thermodynamic function of a new anticancer drug ibrutinib in $\{2-(2-$ ethoxyethoxy)ethanol+water\} mixtures at different temperatures". J Chem Thermody 95: 180-182.

42. Shehatta I (2002) Effect of preferential solvation on the thermodynamic properties of antidepressant drug trazodone in aqueous ethanol: linear free-energy relationships. Helv Chim Acta 85: 2125-2167.

43. Boroujeni HC, Gharib F (2016) Solvatochromism and preferential solvation of deferiprone in some water-organic mixed solvents. J Solution Chem 45: 95-108. 